\title{
CA MARKOV MODELING OF LAND USE LAND COVER CHANGE PREDICTIONS AND EFFECT OF NUMERICAL ITERATIONS, IMAGE INTERVAL (TIME STEPS) ON PREDICTION RESULTS
}

\author{
Md. Surabuddin Mondal ${ }^{1, *}$, Nayan Sharma ${ }^{2}$, Martin Kappas ${ }^{3}$, P. K. Garg ${ }^{4}$ \\ ${ }^{1}$ Dept. of Surveying Engineering, Wollega University, Ethiopia - msk.iit@ gmail.com \\ ${ }^{2}$ Center for Transportation System (CTRANS), Indian Institute of Technology, Roorkee, India - nayanfwt@gmail.com \\ ${ }^{3}$ Dept. of Cartography, GIS \& Remote Sensing, Institute of Geography, Georg-August University of Göttingen, Goldschmidtstr. 5, \\ Room No. 477, 37077, Göttingen, Germany - mkappas@gwdg.de \\ ${ }^{4}$ Dept. of (Geomatics) Engineering, Indian Institute of Technology, Roorkee, India - pkgiitr@ gmail.com
}

Commission III, WG III/7

KEY WORDS: CA Markov Modeling, LULCC Prediction, Time Steps/Image Intervals, Numerical Iterations, Effects on Predictions

\begin{abstract}
:
In this study, land use land cover (LULC) map of 1987, 1997 and 2007 derived from digital satellite images of Landsat - 5 TM of 1987, IRS-1C LISS III images of 1997 and IRS-P6 LISS III images of 2007, respectively, to monitor and predict future LULC scenario. Future LULC has been predicted using CA Markov Model for 2017, 2027 and 2050 by using LULC map of 1987 \& 1997 , $1997 \& 2007$ and $1987 \& 2007$. The period (image interval / time steps) between different predictions years (i.e., 2017, 2027 and 2050 using $1987 \& 1997,1997 \& 2007$ and $1987 \& 2007$ LULC) are 10, 20, 30, 43 and 53 years. The number of iteration was based on the time steps i.e., iterations 20 to predict LULC for 2017 (prediction from 1997 to 2017); iterations 30 for 2027 (prediction from 1997 to 2027); iterations 53 for 2050 (prediction from 1997 to 2050). The relationships (correlations) of quantity of predicted LULC found strong positive correlation for three time periods $(0.981,0.984,0.966$ for $2017,0.981,0.984,0.975$ for $2027,0.977,0.987$, and 0.980 for 2050) and established that there are almost no effect in quantity of prediction results of different time steps (iterations) images and time intervals are used to predict future LULC. The predicting location of predicted LULC of 2017,2027 \& 2050 for the three cases showing positive correlation, where $r$ are $0.728,0.758$ and 0.708 for 2017 - when relatively less time steps used; $r$ are 0.696, 0.761 and 0.674 for 2027 - when medium time steps used; $r$ are $0.599,0.721,0.574$ for 2050 - when more time steps used. The analysis established that although there are nearly no effect on quantitative prediction results but have small impact of iterations (time steps) and time intervals on spatial distribution of predicted LULC results.
\end{abstract}

\section{INTRODUCTION}

CA (Cellular Automata) Markov is a combined of CA and Markov chain land use land cover (LULC) prediction procedure that adds an element of spatial contiguity as well as knowledge of the likely spatial distribution of transition to Markov change analysis. Markov analyses two qualitative land cover images from different dates and produces a transition matrix and CA adds the spatial distribution of the transition. Within CA Markov model, the transition areas file from a Markov Chain analysis of two prior LULC maps establishes the quantity of expected land use and land cover change from each existing category to each other category in the next time period. The basic LULC image (the later land cover image used in the Markov Chain analysis) is used as the starting point for change simulation. Suitability maps (here, evidence likelihood map) establish the inherent suitability of each pixel for each land cover type. However, a contiguity filter down-weights the suitability's of pixels far from existing areas of that class (as of that iteration), thus giving preference to contiguous suitable areas. The number of iterations chosen establishes the number of time steps that will be used in the simulation. Within each time step, each land cover is considered in turn as a host category. All other land cover classes act as claimant classes and compete for land (only within the host class) using the multi-objective land allocation (MOLA) procedure. The area requirements for each claimant class within each host are equal to the total established by the transition areas file divided by the number of iterations. The results of each MOLA operation are overlaid to produce a new LULC map at the end of each iteration. CA Markov automatically normalizes the filter kernel to force the values to sum equal to 1 . This filter is passed over a Boolean image for each class from the current land cover image within each iteration. First, the transition areas file from a Markov chain analysis of two prior LULC maps establishes the quantity of expected land use land cover change (LULCC) from each existing category to each other category in the next time period, and then finally number of iterations chosen establishes the number of time steps that will be used in the simulation. In this study, the spatio-temporal CA Markov model of landscape change using multi-temporal satellite imagery has been used which enabled us to predict spatial pattern of future land use/land cover for the study area - Kamrup Metropolitan district of Assam state in India (Figure 1). For this purpose, land use/land cover maps of the study area have been extracted (digitally classified) from multi temporal satellite images i.e, Landsat MSS image of 1987, Landsat TM image of 1997 and IRS-P6 LISS III image of 2007 (Figure 1 and Table 1). Land use land cover (LULC) maps derived from satellite images of

\footnotetext{
* Corresponding author
} 
1987 and 1997 were used to predict future land use/land cover of 2007.

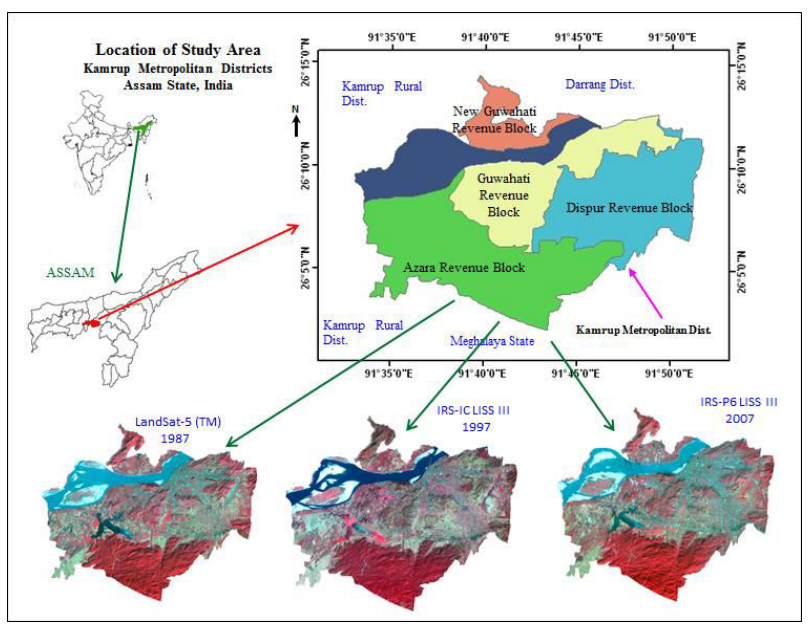

Figure 1. Location and satellite images of study area

\begin{tabular}{|c|c|c|c|}
\hline $\begin{array}{c}\text { Satellite } \\
\& \\
\text { Sensor }\end{array}$ & $\begin{array}{c}\text { Data } \\
\text { Acquired }\end{array}$ & $\begin{array}{c}\text { Spatial } \\
\text { Resolution } \\
(\mathrm{m})\end{array}$ & Spectral Band \\
\hline $\begin{array}{l}\text { LANDSAT - } \\
5 \mathrm{TM}\end{array}$ & $\begin{array}{l}26-12- \\
1987\end{array}$ & $\begin{array}{l}30 \\
(120 \mathrm{~m}- \\
\text { thermal (B } \\
6))\end{array}$ & $\begin{array}{l}\text { B } 1 \text { (blue): } 0.45-0.52 \mu \mathrm{m} \\
\text { B } 2 \text { (green) : } 0.52-0.60 \mu \mathrm{m} \\
\text { B } 3 \text { (red): } 0.63-0.69 \mu \mathrm{m} \\
\text { B } 4 \text { (NIR): } 0.76-0.90 \mu \mathrm{m} \\
\text { B } 5 \text { (SWIR): } 1.55-1.75 \mu \mathrm{m} \\
\text { B } 6 \text { (thermal IR):10.4-12.5 } \\
\mu \mathrm{m} \\
\text { B } 7 \text { (Mid-Infrared) : } 2.08- \\
2.35 \mu \mathrm{m}\end{array}$ \\
\hline $\begin{array}{c}\text { IRS-1C } \\
\text { - LISS-III }\end{array}$ & $\begin{array}{l}05-03- \\
1997\end{array}$ & $\begin{array}{l}23.5 \\
(70 \mathrm{~m}-\mathrm{B} 5 \\
(\mathrm{SWIR}))\end{array}$ & $\begin{array}{l}\text { B } 2 \text { (green) : } 0.52-0.59 \mu \mathrm{m} \\
\text { B } 3 \text { (red): } 0.62-0.68 \mu \mathrm{m} \\
\text { B } 4 \text { (NIR): } 0.77-0.86 \mu \mathrm{m} \\
\text { B } 5 \text { (SWIR): } 1.55-1.70 \mu \mathrm{m}\end{array}$ \\
\hline $\begin{array}{l}\text { IRS-P6 } \\
\text { (Resourcesat- } \\
\text { 1) - LISS-III }\end{array}$ & $\begin{array}{l}14-12- \\
2007\end{array}$ & 23.5 & $\begin{array}{l}\text { B } 2 \text { (green) : } 0.52-0.59 \mu \mathrm{m} \\
\text { B } 3 \text { (red): } 0.62-0.68 \mu \mathrm{m} \\
\text { B } 4 \text { (NIR): } 0.77-0.86 \mu \mathrm{m} \\
\text { B } 5 \text { (SWIR): } 1.55-1.70 \mu \mathrm{m}\end{array}$ \\
\hline
\end{tabular}

Table 1: Details of satellite data used in the study

\section{CALIBRATION OF CA MARKOV MODEL}

In this study, future LULC has been predicted for 2017, 2027 and 2050 using 1987 \& 1997 LULC image and $1997 \& 2007$ LULC image. LULC map of 1987, 1997 and 2007 derived from digital satellite data of Landsat - 5 TM image acquired on Dec. 26 of 1987, IRS-1C LISS III image acquired on March 5 of 1997 and IRS-P6 LISS III image acquired on Dec.14 of 2007, respectively (Figure 2 and Table 2). Future LULC has been also predicted for 2017, 2027 \& 2050 using 1987 \& 2007 LULC image. The period between the first and second images is 10 years and the period to project forward from the second image is 20 years to predict LULC in 2017, 30 years to predict LULC in 2027 and 53 years to predict LULC in 2050 when using 1987 \& 1997 LULC image. The number of time periods between the first and second images is 10 years and the number of time periods to project forward from the second image is 10 years to predict LULC in 2017, 20 years to predict LULC in 2027 and 43 years to predict LULC in 2050 when using 1997 \& 2007 LULC image to predict future LULC. The period between the first and second images is 20 years and the period to project forward from the second image is 10 years to predict LULC in
2017, 20 years to predict LULC in 2027 and 43 years to predict LULC in 2050 when using $1987 \& 2007$ LULC (Table 3).

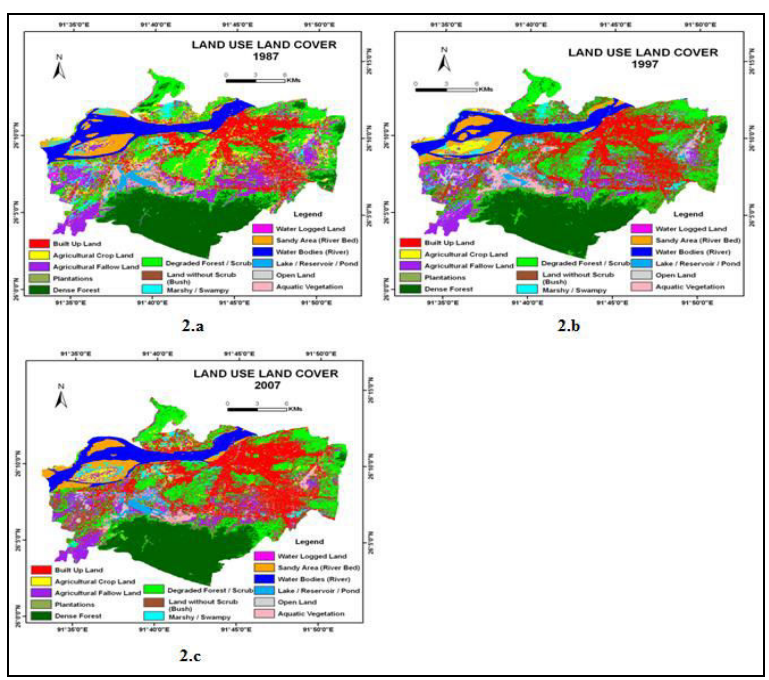

Figure 2. Classified Land Use Land Cover Map of 1987, 1997 and 2007

\begin{tabular}{|l|l|r|r|r|}
\hline $\begin{array}{c}\text { Sl. } \\
\text { No. }\end{array}$ & \multicolumn{1}{|c|}{ Class Name } & \multicolumn{3}{c|}{ Area $\left(\mathbf{k m}^{2}\right)$} \\
\hline & \multicolumn{1}{|c|}{$\mathbf{1 9 8 7}$} & \multicolumn{1}{|c|}{} \\
\hline 1. & Built Up Land & 60.54 & 102.4 & \multicolumn{1}{c|}{141.35} \\
\hline 2. & Agricultural CropLand & 25.91 & 5.99 & 7.17 \\
\hline 3. & Agricultural FallowLand & 48.27 & 34.08 & 25.12 \\
\hline 4. & Plantations & 1.38 & 3.68 & 3.35 \\
\hline 5. & Dense Forest & 86.26 & 80.56 & 74.84 \\
\hline 6. & Degraded Forest & 83.48 & 76.95 & 60.31 \\
\hline 7. & $\begin{array}{l}\text { Land with or without } \\
\text { Scrub }\end{array}$ & 9.48 & 24.82 & 23.78 \\
\hline 8. & Marshy / Swampy & 13.42 & 10.26 & 6.82 \\
\hline 9. & Water Logged Area & 3.57 & 1.86 & 1.52 \\
\hline 10. & Sandy Area (River Bed) & 14.83 & 16.08 & 15.92 \\
\hline 11. & River / Stream & 37.27 & 32.51 & 33.42 \\
\hline 12. & Lake/Reservoir/Pond/Tank & 7.99 & 6.05 & 6.59 \\
\hline 13. & OpenLand & 13.8 & 7.28 & 6.97 \\
\hline 14. & Aquatic Vegetation & 7.78 & 11.46 & 6.82 \\
\hline \multicolumn{1}{|c|}{ Total } & 413.98 & 413.98 & 413.98 \\
\hline
\end{tabular}

Table 2: Area statistics of LULC (land use land cover)

\begin{tabular}{|c|c|c|c|}
\hline $\begin{array}{c}\text { Prediction } \\
\text { for Year }\end{array}$ & Data Used & $\begin{array}{c}\text { Interval } \\
\text { between } \\
\text { the first } \\
\text { and second } \\
\text { images }\end{array}$ & $\begin{array}{c}\text { Time Steps / } \\
\text { Iteration }\end{array}$ \\
\hline \multirow{5}{*}{2017} & $\begin{array}{c}1987 \text { \& 1997 } \\
\text { LULC Map }\end{array}$ & 10 & 20 \\
\cline { 2 - 4 } & $\begin{array}{c}\text { 1997 \& 2007 } \\
\text { LULC Map }\end{array}$ & 10 & 10 \\
\cline { 2 - 4 } & $\begin{array}{c}\text { 1987 \& 2007 } \\
\text { LULC Map }\end{array}$ & 20 & 10 \\
\hline \multirow{5}{*}{2027} & $\begin{array}{c}1987 \text { \& 1997 } \\
\text { LULC Map }\end{array}$ & 10 & 30 \\
\cline { 2 - 4 } & $\begin{array}{c}1997 \text { \& 2007 } \\
\text { LULC Map }\end{array}$ & 10 & 20 \\
\cline { 2 - 4 } & $\begin{array}{c}\text { 1987 \& 2007 } \\
\text { LULC Map }\end{array}$ & 20 & 20 \\
\hline
\end{tabular}




\begin{tabular}{|c|c|c|c|}
\hline \multirow{3}{*}{2050} & $\begin{array}{c}1987 \text { \& 1997 } \\
\text { LULC Map }\end{array}$ & 10 & 53 \\
\cline { 2 - 4 } & $\begin{array}{c}1997 \text { \& 2007 } \\
\text { LULC Map }\end{array}$ & 10 & 43 \\
\cline { 2 - 4 } & $\begin{array}{c}1987 \text { \& 2007 } \\
\text { LULC Map }\end{array}$ & 20 & 43 \\
\hline
\end{tabular}

Table 3. Prediction years, data used, time interval (between the first and second images) and different time steps (iterations)

\subsection{Calibration to Predict LULC in 2017, 2027, 2050 using 1987 \& 1997 LULC Image}

First of all, the model used to predict the LULC of 2017, 2027, 2050 using 1987 \& 1997 LULC image where 1997 LULC is the later (second) image and 1987 LULC image is the previous data. The transition probabilities statistics were generated using classified LULC image of 1987 as first (earlier) image and LULC image of 1997 as later (second) image by using Markov transition estimator to predict LULC of 2017, 2027 and 2050. For this, the number of time interval (periods) between the first and second images is 10 years and the numbers of time steps (iterations) to project forward from the second image are 20 years to predict LULC in 2017, 30 years to predict LULC in 2027 and 53 years to predict LULC in 2050 (Table 3). The transition probabilities matrix were generated using classified LULC image of 1987 as first (earlier) image and LULC image of 1997 as later (second) image. The number of iteration was based on the time steps i.e., iterations 20 to predict LULC for 2017 (prediction from 1997 to 2017); iterations 30 for 2027 (prediction from 1997 to 2027); iterations 53 for 2050 (prediction from 1997 to 2050). This, transition probabilities matrix between LULC of 1987 \& LULC of 1997 is used as an input to CA Markov model. Transition suitability image collections are also used as input to the model.

\subsection{Calibration to Predict LULC for 2017, 2027, 2050 using 1997 \& 2007 LULC Image}

The CA Markov model calibrated to predict LULC of 2017, 2027, and 2050 from classified image of 1997 and 2007. Here 1997 data is the earlier or previous land cover image and 2007 data is later LULC image to predict future LULC. The transition probabilities matrix has been generated using classified LULC image of 1997 as first (earlier) image and LULC image of 2007 as later (second) image to predict future LULC of 2017, 2027 and 2050. The number of time interval (periods) between the first and second images is 10 (years) and the number of time steps (iterations) to project forward from the second image is 10 (years) to predict LULC in 2017, 20 (years) to predict LULC in 2027 and 43 (years) to predict LULC in 2050 (Table 3). Transition probabilities matrix of LULC of 1997 and LULC of 2007, and transition suitability image collection are used as an input to CA Markov model.

\subsection{Calibration to Predict LULC in 2017, 2027, 2050 using 1987 \& 2007 LULC Image}

The CA Markov model also calibrated to predict LULC in 2017, 2027 and 2050 from classified image of 1987(classified earlier LULC image) and 2007 (classified later LULC Image). The transition probabilities matrix has been generated using classified LULC image of 1987 as first (earlier) image and LULC image of 2007 as later (second) image. The number of time interval (periods) between the first and second images is
20 (years) and the number of time steps (iterations) to project forward from the second image is 10 (years) to predict LULC in 2017, 20 (years) to predict LULC in 2027 and 43 (years) to predict LULC in 2050. Transition probabilities matrix between LULC of 1987 \& LULC of 2007 and Transition suitability image collection for all LULC classes are used as an input to CA Markov model.

\subsection{Validation of CA Markov LULC Prediction Results}

The validation for CA Markov model land use/land cover prediction results calculated using various Kappa Index of Agreement (KIA or Kstandard) and related statistical variations on the KIA and showing Kno is 0.8347 , Klocation is 0.859 , Klocation Strata is 0.8591 and Kstandard is 0.7928 .

\section{RESULTS AND ANALYSIS}

A comparative analysis and qualitative and quantitative assessment of all above LULC predictions was done. Relationships (correlations) between predicted quantities of all above LULC predictions have been established. Relationships (correlations) between predicted locations of all above LULC predictions have been also established.

\subsection{Quantity of Prediction}

3.1.1. Quantity of Predicted LULC of 2017, 2027, 2050 using $1987 \& 1997$ LULC Image, using $1997 \& 2007$ LULC Image \& using 1987 \& 2007 LULC Image

Table 4 shows the area statistics of predicted LULC of 2017, 2027, 2050 using $1987 \& 1997$ LULC images, area statistics of predicted LULC of 2017, 2027, 2050 using 1997 \& 2007 LULC images as well as area statistics of predicted LULC of 2017, 2027, 2050 using 1987 \& 2007 LULC images. Figure 3 shows a comparative graphical presentation of overall (total) area statistics of predicted LULC of 2017, 2027, 2050 using 1987 \& 1997 LULC image, using 1997 \& 2007 LULC image and using $1987 \& 2007$ LULC image. Figure 9 also shows a comparative graphical presentation of overall (total) area statistics of the observed LULC of 1987, 1997 and 2007 as well as predicted LULC of 2017, 2027, 2050 using $1987 \& 1997$ LULC image, using 1997 \& 2007 LULC image and using 1987 \& 2007 LULC image.

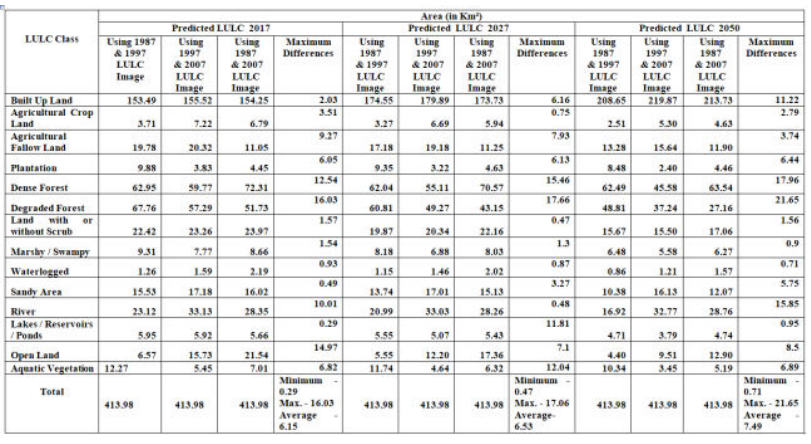

Table 4. Area statistics of predicted LULC of 2017, 2027, 2050

The areas of predicted LULC of 2017 using 1987 \& 1997 LULC image, using 1997 \& 2007 LULC image and using 1987 \& 2007 LULC image are slightly different from each other. Here, the differences of predicted LULC range between 0.29 $\mathrm{km}^{2}$ to $16.03 \mathrm{~km}^{2}$ only, average is $6.15 \mathrm{~km}^{2}$. The areas of 
predicted LULC of 2027 using 1987 \& 1997 LULC image, using $1997 \& 2007$ LULC image and using 1987 \& 2007 LULC image are slightly different from each other which range between $0.47 \mathrm{~km}^{2}$ to $17.66 \mathrm{~km}^{2}$ only, average is $6.53 \mathrm{~km}^{2}$. The areas of predicted LULC of 2050 using 1987 \& 1997 LULC image, using 1997 \& 2007 LULC image and using 1987 \& 2007 LULC image are slightly different from each other. Here, the differences of predicted LULC range between $0.71 \mathrm{~km}^{2}$ to $21.65 \mathrm{~km}^{2}$ only and average is $7.49 \mathrm{~km}^{2}$. These differences are small $\left(0.29 \mathrm{~km}^{2}\right.$ to $16.03 \mathrm{~km}^{2}, 0.47 \mathrm{~km}^{2}$ to $17.66 \mathrm{~km}^{2}, 0.71 \mathrm{~km}^{2}$ to $21.65 \mathrm{~km}^{2}$ ) in a study area of $413.98 \mathrm{~km}^{2}$.

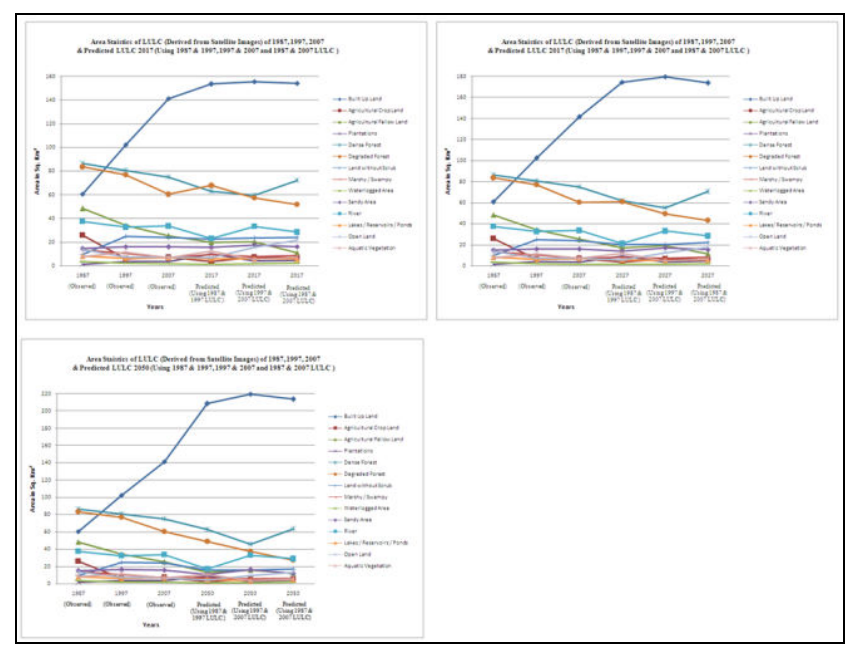

Figure 3. Line graphs represent area statistics of the observed LULC of 1987, $1997 \& 2007$ as well as predicted LULC of 2017, 2027, 2050 using $1987 \& 1997$ LULC image, using 1997 \& 2007 LULC image and using 1987 \& 2007 LULC image

\subsubsection{Correlations between Predicted Quantities}

3.1.2.1. Correlations between Area of Predicted LULC of 2017 using 1987 \& 1997 LULC Image, Area of Predicted LULC of 2017 using $1997 \& 2007$ LULC Image and Area of Predicted LULC of 2017 using 1987 \& 2007 LULC Image

The correlation between area of predicted LULC of 2017 using 1987 \& 1997 LULC images and area of predicted LULC of 2017 using 1997 \& 2007 LULC images is strong, where $\mathrm{R}^{2}$ is 0.981. Correlation between area of predicted LULC of 2017 using 1997 \& 2007 LULC images and area of predicted LULC of 2017 using $1987 \& 2007$ LULC images is also strong, where $\mathrm{R}^{2}$ is 0.984 . The Correlation between area of predicted LULC of 2017 using 1987 \& 1997 LULC images and area of predicted LULC of 2017 using 1987 \& 2007 LULC images is strong, where $\mathrm{R}^{2}$ is 0.966 (Table 5, Figure 4).

3.1.2.2. Correlations between Area of Predicted LULC of 2027 using 1987 \& 1997 LULC Image, Area of Predicted LULC of 2027 using $1997 \& 2007$ LULC Image and Area of Predicted LULC of 2027 using 1987 \& 2007 LULC Image

The correlation between area of predicted LULC of 2027 using 1987 \& 1997 LULC images \& area of predicted LULC of 2027 using $1997 \& 2007$ LULC images is strong, where $\mathrm{R}^{2}$ is 0.982 . Correlation between area of predicted LULC of 2027 using 1997 \& 2007 LULC images and area of predicted LULC of 2027 using 1987 \& 2007 LULC images is also strong, where $\mathrm{R}^{2}$ is 0.985 . The Correlation between area of predicted LULC of
2027 using 1987 \& 1997 LULC images and area of predicted LULC of 2027 using 1987 \& 2007 LULC images is strong, where $\mathrm{R}^{2}$ is 0.975 (Table 5, Figure 5).

3.1.2.3. Correlations between area of Predicted LULC of 2050 using 1987 \& 1997 LULC Image, Area of Predicted LULC of 2050 using $1997 \& 2007$ LULC Image and Area of Predicted LULC of 2050 using 1987 \& 2007 LULC Image

The correlation between area of predicted LULC of 2050 using 1987 \& 1997 LULC images and area of predicted LULC of 2050 using $1997 \& 2007$ LULC images is strong, where $\mathrm{R}^{2}$ is 0.977. Correlation between area of predicted LULC of 2050 using $1997 \& 2007$ LULC images and area of predicted LULC of 2050 using $1987 \& 2007$ LULC images is also strong, where $\mathrm{R}^{2}$ is 0.987 . The Correlation between area of predicted LULC of 2050 using 1987 \& 1997 LULC images and area of predicted LULC of 2050 using 1987 \& 2007 LULC images is strong, where $R^{2}$ is 0.980 (Table 5, Figure 6).

\begin{tabular}{|c|c|c|c|}
\hline $\begin{array}{c}\text { Correlation } \\
\text { between area } \\
\text { of predicted } \\
\text { LULC }\end{array}$ & $\begin{array}{c}\text { Correlation } \\
\left(\mathbf{R}^{2}\right) \\
\text { for 2017 }\end{array}$ & $\begin{array}{c}\text { Correlation } \\
\left(\mathbf{R}^{2}\right) \\
\text { for 2027 }\end{array}$ & $\begin{array}{c}\text { Correlation } \\
\left(\mathbf{R}^{2}\right) \\
\text { for 2050 }\end{array}$ \\
\hline $\begin{array}{c}\text { Using 1987 \& } \\
\text { 1997 LULC } \\
\text { Image } \\
\text { and }\end{array}$ & 0.981 & 0.982 & 0.977 \\
$\begin{array}{c}\text { Using 1997 \& } \\
\text { 2007 LULC } \\
\text { images }\end{array}$ & & & \\
\hline $\begin{array}{c}\text { Using 1997 \& } \\
\text { 2007 LULC } \\
\text { Image } \\
\text { and }\end{array}$ & 0.984 & 0.985 & 0.987 \\
$\begin{array}{c}\text { Using 1987 \& } \\
\text { 2007 LULC } \\
\text { images }\end{array}$ & & & \\
\hline $\begin{array}{c}\text { Using 1987 \& } \\
\text { 1997 LULC } \\
\text { Image } \\
\text { and }\end{array}$ & 0.966 & 0.975 & \\
$\begin{array}{c}\text { Using 1987 \& } \\
\text { 2007 LULC } \\
\text { images }\end{array}$ & & & \\
\hline
\end{tabular}

Table 5. Correlations of between area of predicted LULC using 1987 \& 1997 LULC image, area of predicted LULC using 1997 \& 2007 LULC image \& area of predicted LULC using 1987 \& 2007 LULC image

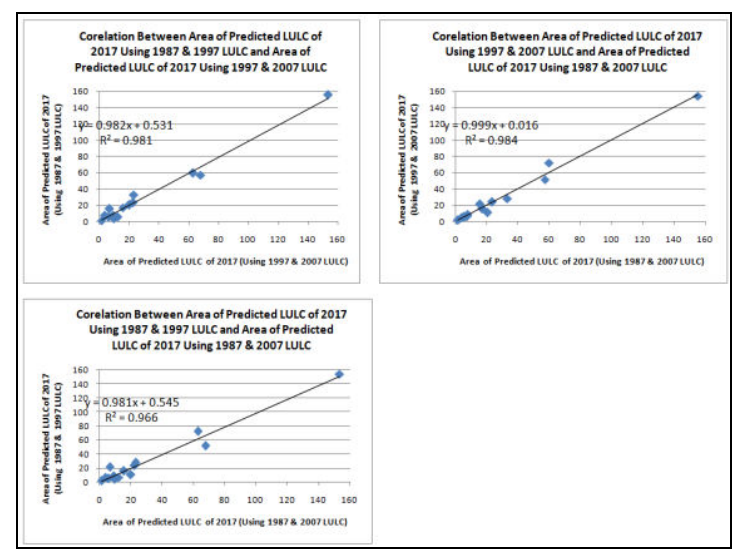


Figure 4. Relationships between area statistics of predicted LULC of 2017 using 1987 \& 1997 LULC image, area statistics of predicted LULC of 2017 using 1997 \& 2007 LULC image and area statistics of predicted LULC of 2017 using 1987 \& 2007 LULC image

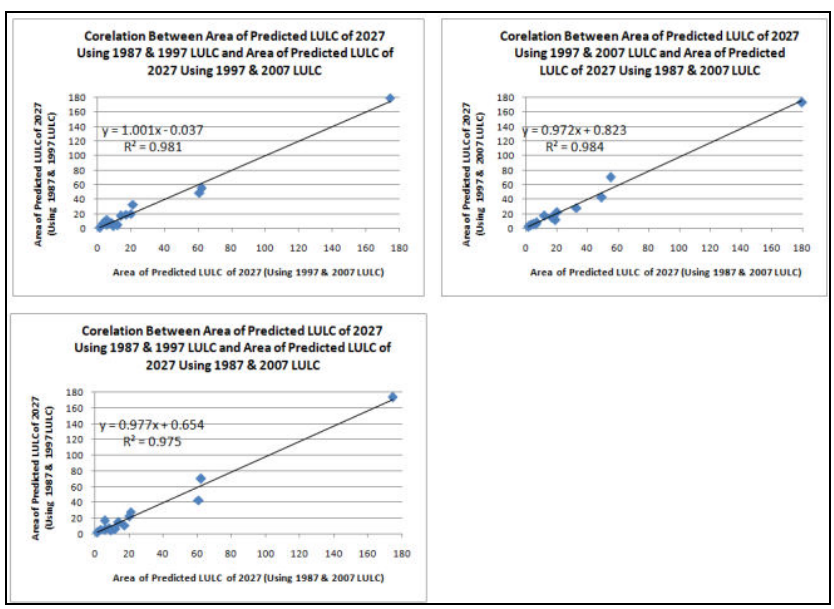

Figure 5. Relationships between area statistics of predicted LULC of 2027 using 1987 \& 1997 LULC image, area statistics of predicted LULC of 2027 using 1997 \& 2007 LULC image and area statistics of predicted LULC of 2027 using 1987 \& 2007 LULC image

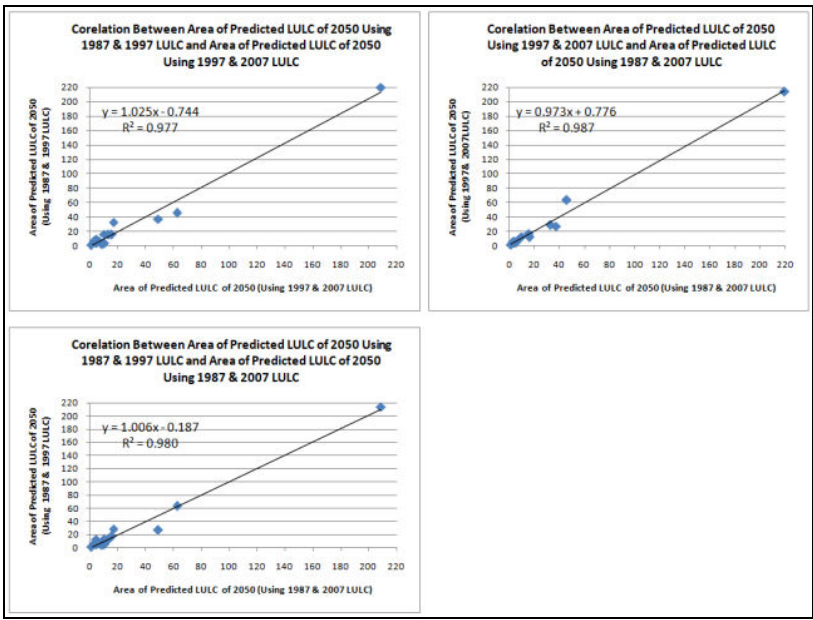

Figure 6. Relationships between area statistics of predicted LULC of 2050 using $1987 \& 1997$ LULC image, area statistics of predicted LULC of 2050 using 1997 \& 2007 LULC image and area statistics of predicted LULC of 2050 using $1987 \&$ 2007 LULC image

\subsection{Allocation of Prediction}

3.2.1. Allocation of Predicted LULC of 2017, 2027, 2050 using 1987\& 1997 LULC Image, using 1997 \& 2007 LULC Image and using 1987 \& 2007 LULC Image

Figure 7 shown allocation of predicted LULC of 2017 using 1987 \& 1997 LULC images, using 1997 \& 2007 LULC images and using 1987 \& 2007 LULC images. Figure 8 shown allocation of predicted LULC of 2027 using 1987 \& 1997 LULC images, using 1997 \& 2007 LULC images and using 1987 \& 2007 LULC images. Figure 9 shown allocation of predicted LULC of 2050 using 1987 \& 1997 LULC images, using 1997 \& 2007 LULC images and using 1987 \& 2007 LULC images.

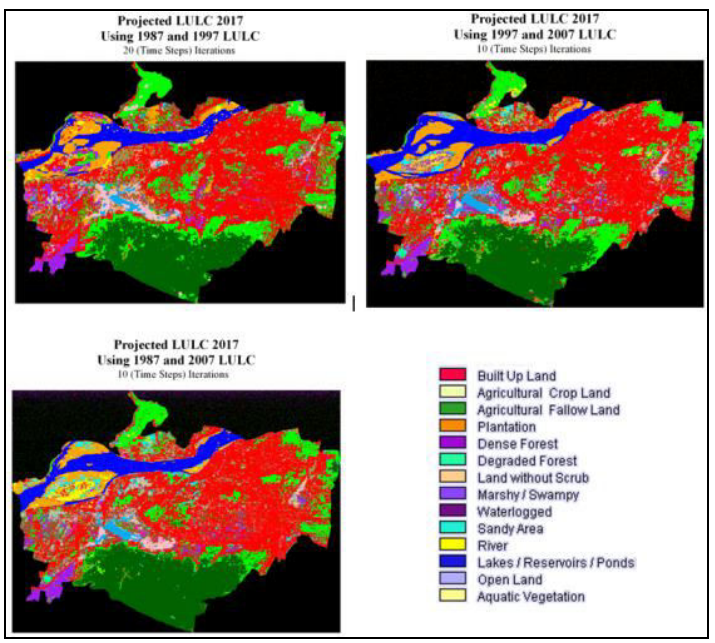

Figure 7. Predicted LULC of 2017 using 1987 \& 1997 LULC image, using 1997 \& 2007 LULC image and using 1987 \& 2007 LULC image

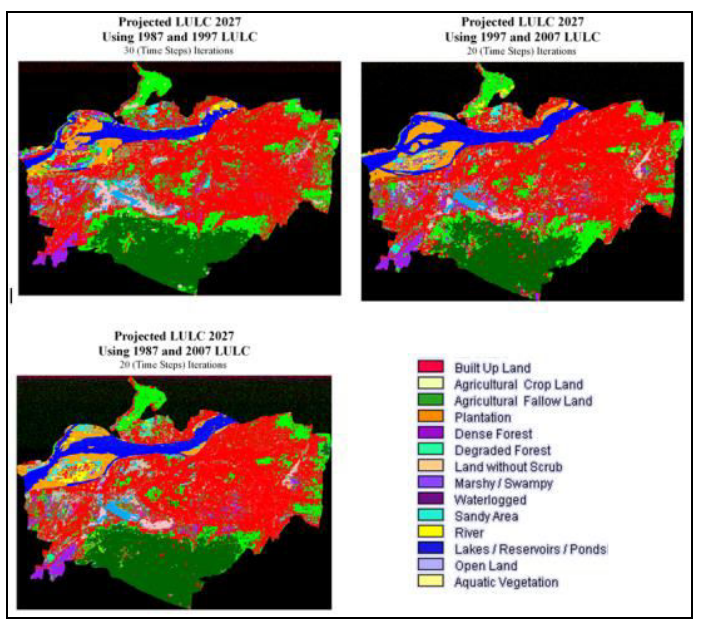

Figure 8. Predicted LULC of 2027 using 1987 \& 1997 LULC image, using 1997 \& 2007 LULC image and using 1987 \& 2007 LULC image

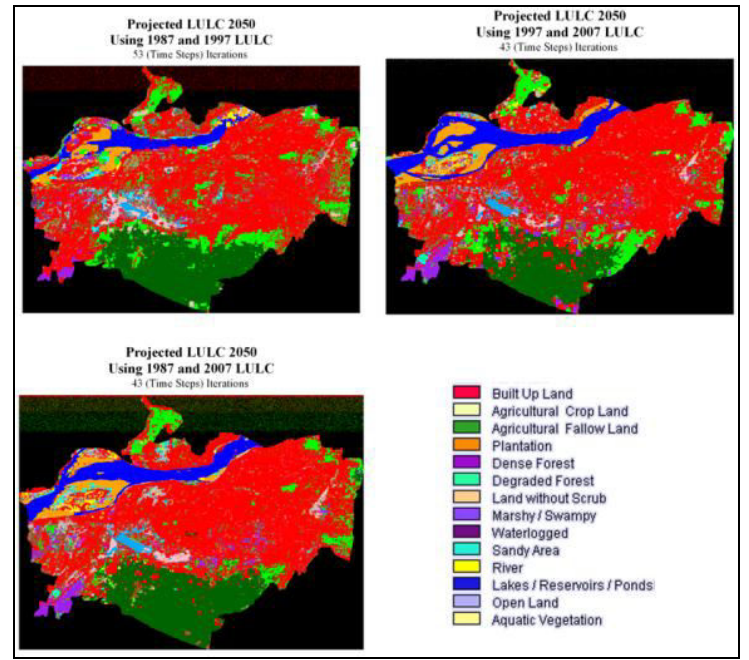


Figure 9. Predicted LULC of 2050 using 1987 \& 1997 LULC image, using 1997 \& 2007 LULC image and using 1987 \& 2007 LULC image

\subsubsection{Correlations between Predicted Locations}

3.2.2.1. Correlations between Location of Predicted LULC of 2017 using $1987 \& 1997$ LULC Image, Location of Predicted LULC of 2017 using 1997 \& 2007 LULC Image and Location of Predicted LULC of 2017 using 1987 \& 2007 LULC Image

The area statistics of different predicted LULC of 2017, $2027 \&$ 2050 (using 1987 \& 1997 LULC, using 1997 \& 2007 LULC and using 1987 \& 2007 LULC) shows that there are not much of differences. But the spatial differences between predicted LULC of 2017 using 1987 \& 1997 LULC, using 1997 \& 2007 LULC and using $1987 \& 2007$ LULC are found different. Regression analysis of three pairs of images (predicted LULC of 2017 using 1987 \& 1997 LULC images and using 1997 \& 2007 LULC images; predicted LULC of 2017 using 1997 \& 2007 LULC images and using 1987 \& 2007 LULC images; predicted LULC of 2017 using 1987 \& 1997 LULC images and using $1987 \& 2007$ LULC images) established that they are spatially different. Spatial regressions correlation coefficient $\left(\mathrm{R}^{2}\right)$ is 0.728 between predicted LULC class of 2017 using 1987 \& 1997 LULC images \& predicted LULC class of 2017 using 1997 \& 2007 LULC images. The correlation coefficient $\left(\mathrm{R}^{2}\right)$ is 0.758 between predicted LULC class of 2017 using 1997 \& 2007 LULC images \& predicted LULC class of 2017 using $1987 \& 2007$ LULC images. The correlation coefficient $\left(\mathrm{R}^{2}\right)$ is 0.708 between predicted LULC class of 2017 using 1987 \& 1997 LULC images and predicted LULC class of 2017 using $1987 \& 2007$ LULC images. All the three cases show positive but weak correlation as $0.728,0.758$, and 0.708 , respectively (Figure 10.a, Figure 10.b, and Figure 10.c). It is established that spatially they have some differences. It is established that there have some effects in spatial distribution of predicted LULC of 2017 when different time steps (iterations) images are used to predict future LULC.

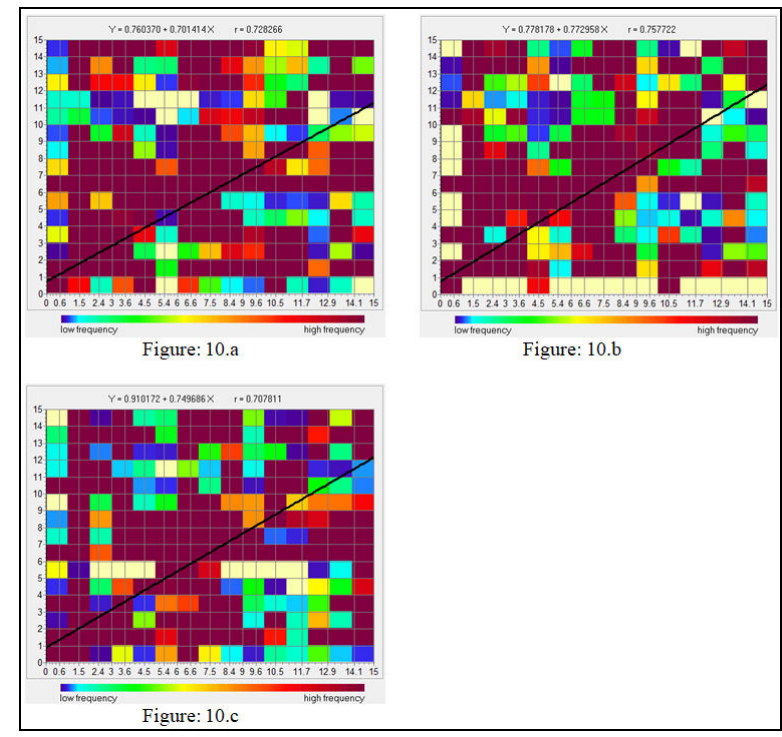

Figure 10.a. Relationships between predicted LULC of 2017 using 1987 \& 1997 LULC image and predicted LULC of 2017 using 1997 \& 2007 LULC image; Figure 10.b. Relationships between predicted LULC of 2017 using 1997 \& 2007 LULC image and predicted LULC of 2017 using 1987 \& 2007 LULC image; Figure 10.c. Relationships between predicted LULC of 2017 using $1987 \& 1997$ LULC image and predicted LULC of 2017 using 1987 \& 2007 LULC image

3.2.2.2. Correlations between Location of Predicted LULC of 2027 using $1987 \& 1997$ LULC Image, Location of Predicted LULC of 2027 using $1997 \& 2007$ LULC Image and Location of Predicted LULC of 2027 using 1987 \& 2007 LULC Image

The spatial differences between predicted LULC of 2027 using 1987 \& 1997 LULC, using 1997 \& 2007 LULC and using 1987 \& 2007 LULC are found different. Regression analysis of three pairs of images (predicted LULC of 2027 using 1987 \& 1997 LULC images and using 1997 \& 2007 LULC images; predicted LULC of 2027 using 1997 \& 2007 LULC images and using $1987 \& 2007$ LULC images; predicted LULC of 2027 using 1987 \& 1997 LULC images and using 1987 \& 2007 LULC images) established that they are spatially different. Spatial regressions correlation coefficient $\left(\mathrm{R}^{2}\right)$ is 0.696 between predicted LULC class of 2027 using 1987 \& 1997 LULC images \& predicted LULC class of 2027 using 1997 \& 2007 LULC images. The correlation coefficient $\left(\mathrm{R}^{2}\right)$ is 0.761 between predicted LULC class of 2027 using 1997 \& 2007 LULC images and predicted LULC class of 2027 using 1987 \& 2007 LULC images. The correlation coefficient $\left(\mathrm{R}^{2}\right)$ is 0.674 between predicted LULC class of 2027 using 1987 \& 1997 LULC images and predicted LULC class of 2027 using 1987\& 2007 LULC images. All the three cases show positive but weak correlation as $0.696,0.761$, and 0.674 , respectively (Figure 11.a, Figure 11.b, and Figure 11.c). It is also established that spatially they have some differences. It is established that there have some effects in spatial distribution of predicted LULC of 2027 when different time steps (iterations) images are used to predict future LULC.

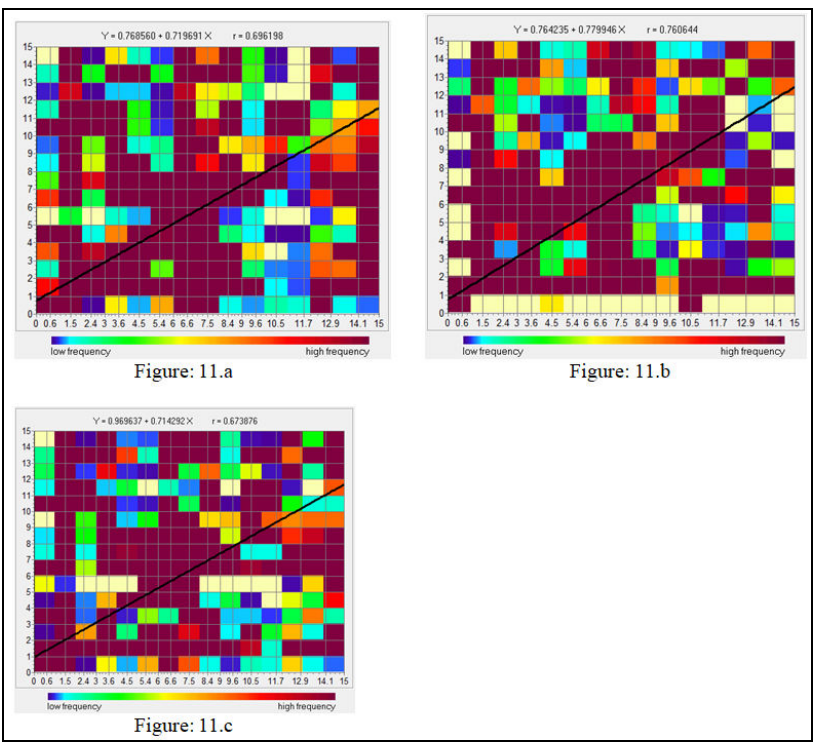

Figure 11.a. Relationships between predicted LULC of 2027 using $1987 \& 1997$ LULC image and predicted LULC of 2027 using 1997 \& 2007 LULC image; Figure 11.b: Relationships between predicted LULC of 2027 using 1997 \& 2007 LULC image and predicted LULC of 2027 using 1987 \& 2007 LULC image; Figure 11.c: Relationships between predicted LULC of 2027 using $1987 \& 1997$ LULC image and predicted LULC of 2027 using 1987 \& 2007 LULC image 
3.2.2.3. Correlations between Location of Predicted LULC of 2050 using $1987 \& 1997$ LULC Image, Location of Predicted LULC of 2050 using 1997 \& 2007 LULC Image and Location of Predicted LULC of 2050 using $1987 \& 2007$ LULC Image

The spatial differences between predicted LULC of 2050 using 1987 \& 1997 LULC, using 1997 \& 2007 LULC and using 1987 \& 2007 LULC are found different. Regression analysis of three pairs of images (predicted LULC of 2050 using 1987 \& 1997 LULC images and using $1997 \& 2007$ LULC images; predicted LULC of 2050 using 1997 \& 2007 LULC images and using 1987 \& 2007 LULC images; predicted LULC of 2050 using 1987 \& 1997 LULC images and using 1987 \& 2007 LULC images) established that they are spatially different. Spatial regressions correlation coefficient $\left(\mathrm{R}^{2}\right)$ is 0.60 between predicted LULC class of 2050 using 1987 \& 1997 LULC images and predicted LULC class of 2027 using 1997 \& 2007 LULC images. The correlation coefficient $\left(\mathrm{R}^{2}\right)$ is 0.721 between predicted LULC class of 2050 using 1997 \& 2007 LULC images \& predicted LULC class of 2050 using 1987 \& 2007 LULC images. The correlation coefficient $\left(\mathrm{R}^{2}\right)$ is 0.574 between predicted LULC class of 2050 using 1987 \& 1997 LULC images and predicted LULC class of 2050 using 1987 \& 2007 LULC images. All the three cases show positive but weak correlation as $0.60,0.721$, and 0.574 , respectively (Figure 12.a, Figure 12.b, and Figure 12.c). It is also established that spatially they have some differences. It is established that there have some effects in spatial distribution of predicted LULC of 2050 when different time steps (iterations) images are used to predict future LULC.

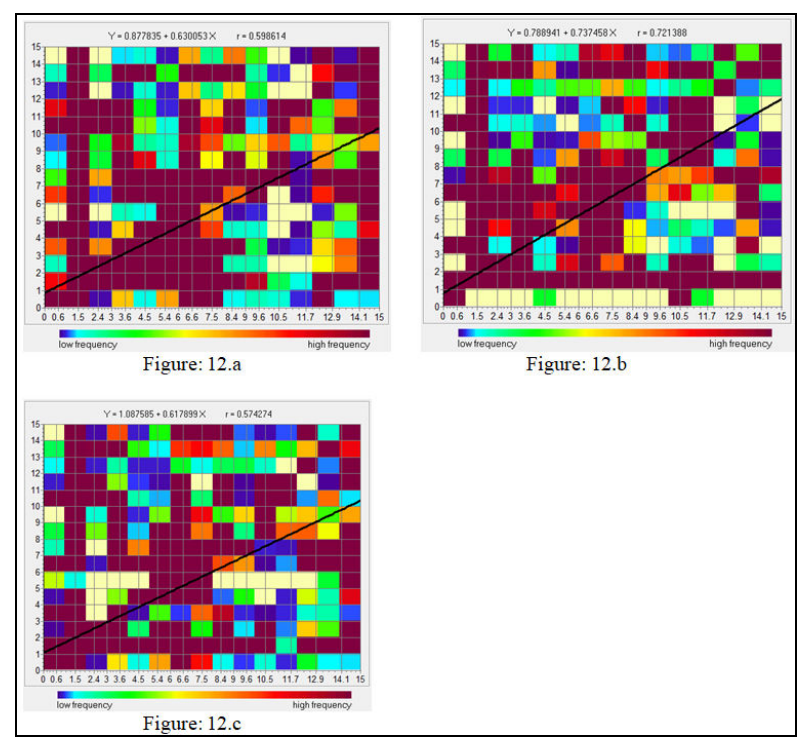

Figure 12.a. Relationships between predicted LULC of 2050 using 1987 \& 1997 LULC image and predicted LULC of 2050 using 1997 \& 2007 LULC image; Figure 12.b. Relationships between predicted LULC of 2050 using 1997 \& 2007 LULC image and predicted LULC of 2050 using 1987 \& 2007 LULC image; Figure 12.c. Relationships between predicted LULC of 2050 using 1987 \& 1997 LULC image and predicted LULC of 2050 using $1987 \& 2007$

In all the above three cases i.e., location predicted LULC of 2017, 2027, 2050 show positive but weak correlation (Table 6). It is also established that spatially they have some differences. It is established that there have some effects in spatial distribution of predicted LULC of 2017, 2027, 2050 when different time steps (iterations) and time intervals images are used to predict future LULC.

\begin{tabular}{|c|c|c|c|}
\hline $\begin{array}{c}\text { Correlation } \\
\text { between } \\
\text { area of } \\
\text { predicted } \\
\text { LULC }\end{array}$ & $\begin{array}{c}\text { Correlation } \\
\left(\mathbf{R}^{2}\right) \\
\text { for } 2017\end{array}$ & $\begin{array}{c}\text { Correlation } \\
\left(\mathbf{R}^{2}\right) \\
\text { for } 2027\end{array}$ & $\begin{array}{c}\text { Correlation } \\
\left(R^{2}\right) \\
\text { for } 2050\end{array}$ \\
\hline $\begin{array}{c}\text { Using } 1987 \\
\& 1997 \\
\text { LULC Image } \\
\text { and } \\
\text { Using } 1997 \\
\& 2007 \\
\text { LULC } \\
\text { images } \\
\end{array}$ & 0.728 & 0.696 & 0.599 \\
\hline $\begin{array}{c}\text { Using } 1997 \& \\
2007 \text { LULC } \\
\text { Image } \\
\text { and } \\
\text { Using 1987\& } \\
2007 \text { LULC } \\
\text { images } \\
\end{array}$ & 0.758 & 0.761 & 0.721 \\
\hline $\begin{array}{c}\text { Using } 1987 \\
\& 1997 \\
\text { LULC Image } \\
\text { and } \\
\text { Using } 1987 \\
\& 2007 \\
\text { LULC } \\
\text { images }\end{array}$ & 0.708 & 0.674 & 0.574 \\
\hline
\end{tabular}

Table 6. Correlations of between location of predicted LULC using 1987 \& 1997 LULC image, location of predicted LULC using $1997 \& 2007$ LULC image and location of predicted LULC using 1987 \& 2007 LULC image

\section{CONCLUTIONS}

This approach presented in this chapter examines if there is any effect in LULC prediction results when different time interval and time steps (iteration) are used. When the quantity of predicted LULC of 2017, 2017 \& 2050 (using 1987 \& 1997 LULC, using 1997 \& 2007 LULC and using 1987 \& 2007 LULC) changes are analyzed, they are found to have also strong positive correlation for three time periods (i.e., 0.981, 0.984, 0.966 for $2017,0.981,0.984,0.975$ for $2027,0.977,0.987$, and 0.980 for 2050). Firstly, these strong correlations established that there is almost no effect in quantity of prediction results different time steps (iterations) images and time intervals used to predict future LULC. Secondly, the predicting location of predicted LULC of $2017,2027 \& 2050$ for the three cases showing positive correlation $(0.728,0.758$ and 0.708 for 2017 - when relatively less time steps used; $0.696,0.761$ and 0.674 for 2027 - when using medium time steps used; 0.599, 0.721, 0.574 for 2050 - when using more time steps used). It proves that there have some effects in spatial distribution of predicted LULC when different time steps (iterations) images are used to predict future LULC. The results also indicate that relatively less time steps (iteration) produced spatially more accurate results. Whereas, more time steps (iteration) produce spatially less accurate results. The results also indicate less time intervals produced spatially more accurate results; whereas, more time intervals produce spatially less accurate results. The results also 
indicate that combination of less time steps (iteration) and less time intervals produced spatially most accurate results. Overall from the present study results, it is found that there is nearly no effect in quantity of prediction results when different time steps (iterations) and time intervals images are used to predict future LULC but there have some effect in spatial distribution of predicted LULC when we use different time steps (iterations) and time intervals images to predict future LULC. It is also established that this approach can be used examines if there is any effect in CA Markov LULC prediction results when different time interval and time steps (iteration) are used.

\section{ACKNOWLEDGEMENTS}

The authors are thankful to EU for financial support received to carry out this study.

\section{REFERENCES}

Agarwal C., Green G.M., Grove J.M., Evans T.P., Schweik C.M., 2002, A review and assessment of land-use change models: dynamics of space, time, and human choice, Gen. Tech. Rep. NE-297, Newton Square, PA: U.S. Department of Agriculture, Forest Service, Northeastern Research Station, pp. 61 .

Geoghegan, J., Wainger, L. A. and Bocksael, N.E., 1997, Spatial landscape indices in a hedonic framework. An ecological economics analysis using GIS. Ecological Economics, 23, pp. 251-264.

Lambin, E. F., Geist H. I. and Lepers E. , 2003, Dynamics of land use and land cover change in tropical regions. Annual Review of Environment and Resources, 28, pp. 205-241.

Mertens, B. and Lambin E. F., 1997, Spatial modeling of deforestation in Southern Cameroon. Applied Geogr., 17, pp. 143-162.

Mondal M. S., Sharma N., Kappas M., Garg P. K., 2012, Modeling of spatiotemporal dynamics of LULC - a review and assessment. Journal of Geomatics, 6(2), pp. 93-103.

Muller M.R. and Middleton J., 1994, A Markov model of landuse change dynamics in the Niagara region, Ontario, Canada, Land-scape Ecology, 9(2), pp. 151-157.

Pontius Jr., R. G., Agarwal A. and Huffaker D., 2003, Estimating the uncertainty of land cover extrapolations while constructing a raster map from tabular data. Journal of Geographic System, 5, pp. 253-273.

Pontius Jr., R. G., 2002, Statistical methods to partition effects of quantity and location during comparison of categorical maps at multiple resolutions. Photogrammetric Engineering \& Remote Sensing, 68(10), pp. 1041-1049.

Weng, Q., 2002, Land use change analysis in the Zhujiang Delta of China using satellite remote sensing, GIS and stochastic modelling. Journal of environmental Management, 64, pp. 273-284. 